\title{
STRUCTURAL BEHAVIOR OF PRECAST HIGH STRENGTH REINFORCED CONCRETE VIERENDEEL TRUSS WALLS: A NUMERICAL APPROACH
}

\author{
Hadi Naser Ghadhban Al-Maliki ${ }^{1}$, Ali Al-Balhawi ${ }^{1}$, Salwa R. Al-Taai ${ }^{1}$, Huda M. Madhloom ${ }^{1}$, and ${ }^{*}$ Yaser \\ Gamil $^{2}$
}

${ }^{1}$ Civil Engineering Department, Engineering College, Mustansiriyah University, Baghdad, Iraq; ${ }^{2}$ Building Materials, Structural and Fire Engineering Department of Civil, Environmental and Natural Resources Engineering, Luleå University of Technology, Sweden

*Corresponding Author, Received: 04 April 2021, Revised: 09 May 2021, Accepted: 12 June 2021

\begin{abstract}
Reinforced concrete (RC) walls have been widely used in different types of civil engineering projects. Therefore, their behaviour under several kinds of loading is of utmost importance. In this study, the main objective is to investigate the behaviour of RC Vierendeel walls under the applied loads by employing numerical analyses for the studied walls. Several assumptions are adopted in these analyses to simulate the actual behaviour of Vierendeel walls, which were experimentally studied in previous investigations. The numerical results showed that the simulated numerical behaviour has a very good agreement with the experimental results of the tested models. Statically, this agreement is validated and verified in terms of the mean and standard deviation values. Therefore, the proposed numerical models and assumptions are the suitable ones to simulate the structural behaviour of these walls under the applied conditions. The structural behaviour is presented in terms of load capacity, crack pattern, deflection, and mode of failure. The results show that the reactive powder concrete (RPC) models have more resistance under the applied load in terms of deflection, cracks, and ductility index than the models of normal strength concrete (NSC). Also, the openings are the main reason for the diagonal cracking at the corners of the RC walls. The deflection in all models is a single curvature. The mode of failure for all models is shear.
\end{abstract}

Keywords: Numerical Approach, Precast Concrete, High Strength Reinforced Concrete, ANSYS, Reactive Powder Concrete, Normal Strength Concrete, Vierendeel Truss Walls.

\section{INTRODUCTION}

$\mathrm{RC}$ wall is one of the most crucial members of many civil engineering projects. Therefore, many studies have been conducted to investigate the behaviour of different types of walls under several kinds of loads. In general, when a concrete member is subjected to load, the deformation gradually increases with time and it may be many times greater than the instant value. Usually, RC walls are commonly used as structural elements in locations where they are subjected to axial loads, lateral loads and moments [1-4].

There are many parameters, which can affect the structural behaviour of the concrete wall panels. These parameters include the wall's geometry and material properties, support conditions, and the applied loading [1,2]. Typically, the design of the RC structure mainly includes two limit states, which should be satisfied, i.e. strength and serviceability. The former limit is the capability of the designed structure to safely stand under different types of loads. However, the latter limit is the ability of the structure to carry working loads with taking into account the cracking and deflection issues [5].
RC walls have been widely used in different types of civil engineering projects. Therefore, their behaviour under several kinds of loading is of utmost importance. In this study, numerical analyses for a specific type of wall are employed to investigate the behaviour of RC Vierendeel walls under the applied loads. Several assumptions are adopted in these analyses to simulate the actual behaviour of Vierendeel walls, which were experimentally studied in previous investigations.

\section{TYPES OF REINFORCED CONCRETE WALLS}

A- The American Code ACI-318 [6] divides the structural walls into bearing and non-bearing. For example, the bearing wall is defined as a member that can sustain under vertical load, which can be more than the designed ones. Also, the structural walls can be classified as:

i. Bearing walls are designed to carry mainly in-plane vertical loads. Hence, the vertical load can have eccentrically concerning the wall thickness.

ii. Shear walls are usually designed to resist lateral loads including wind and earthquakes along with the gravity loads, 
which act on structures.

iii. Non-bearing walls are defined as members that can support their weight only.

iv. Tilt-up walls are defined as slender members, which are cast in a horizontal position and then tilted to their intended vertical position and attached to the structure. These walls are usually designed to carry compound loads, e.g. vertical and lateral [7].

B- The British Standard BS 8110 [8] defines the wall as an in-plane load-bearing member, which its length exceeding 4 times its thickness. This condition is used to distinguish between walls and columns [8]. There are two popular types of defined concrete walls according to BS 8110 [8] as follows:

i. RC wall is designed to contain the least amount of steel reinforcement ratio. This ratio is determined according to the required wall strength.

ii. The plain concrete wall is an element that has either no reinforcement or inadequate reinforcement to control cracking. Therefore, any reinforcement can be ignored in assessing the wall strength.

Also, BS 8110 [8] classifies other concrete walls as follows:

i. A braced wall is resisted lateral forces by the attached lateral supports, i.e. floors and cross-walls.

ii. Un-braced wall has its lateral stability, e.g. cantilever wall.

iii. The stocky wall is defined as the ratio of effective height divided by the thickness (h/t) that does not exceed 15 and 10 for braced and unbraced walls, respectively.

iv. A slender wall can be indicated by the ratio of the above stocky wall.

In practice, bearing walls are popularly used for different types of structures such as residential buildings, warehouses, low and high -rise commercial buildings of concrete, masonry, and wood construction. Walls can be cast by two main methods such as a precast unit or cast in-site due to the adopted design and processes of construction [9].

\section{VIERENDEEL TRUSS}

RC frames include horizontal elements in terms of beams, vertical elements in terms of columns, which are monolithically cast and connected by rigid joints. In general, RC frames are supposed to resist different types of loading, i.e. gravity and lateral loads through the structural behaviour of beams and columns in bending and they are used to prevent rotations in the structures. Also, the system of the frame structure is commonly chosen to design office and residential buildings [10]. Similarly, Vierendeel is a type of frame, which consists of members. The shape of the Vierendeel truss is not similar to that of a typical truss with connecting triangular unit because the diagonals or bracings are not used in the former truss. However, the web and chords elements of the Vierendeel truss are mainly used to stabilize the truss [11-13]. Moreover, the Vierendeel truss provides an aesthetic shape and has a limited number of elements that are connected at joints [14].

Also, it is easy to form and cast in place or pre-casted. RC frames are commonly used in constructions. However, Vierendeel frames are necessary to be used in structures where open spaces are required between the top and bottom chords [9]. The main aim of the present paper is to simulate the structural behaviour of RC Vierendeel truss wall of different strengths with an opening under eccentric loading. This structural analysis is performed by using ANSYS software [15] for the tested models of the previous study [16]. The structural response parameters in terms of load capacity, cracks pattern, deflection, and mode of failure of all models are evaluated and discussed. Hence, various types of Vierendeel truss can be shown in Fig. 1.

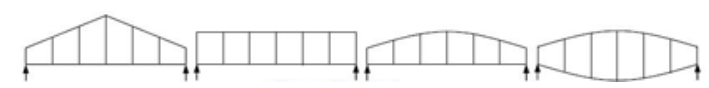

(a)

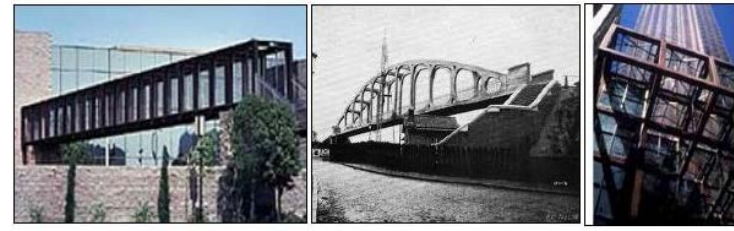

(b)

Fig.1 Various types of Vierendeel truss, (a) Types of Vierendeel girders, and (b) Practical applications of Vierendeel [17]

\section{LITERATURE REVIEW}

This section includes a review of the previous studies about RC wall panels, Vierendeel truss walls, self-compacted concrete, and reactive powder concrete. Basically, the structural behaviour of a structure depends on its geometry, material characteristics, support conditions, and the applied loading. In general, the applied loads on wall panels include in-plane and axial loads.

The behaviour of RC wall panels includes two types of curves, which depend on the supports of their edges. For example, a restrained wall in top and bottom with or without opening behaves in one-way action where the uniaxial curvature in the direction of loading occurs and the cracking 
appears in the parallel direction of loading as shown in Fig. 2-a. However, when the wall is under axial loads and restrained on all sides can behave in two-way action as shown in Fig. 2-b. These side supports are caused biaxial curvatures to occur. Also, the cracking in this axially loaded wall is in the two parallel and perpendicular directions of loading [18].

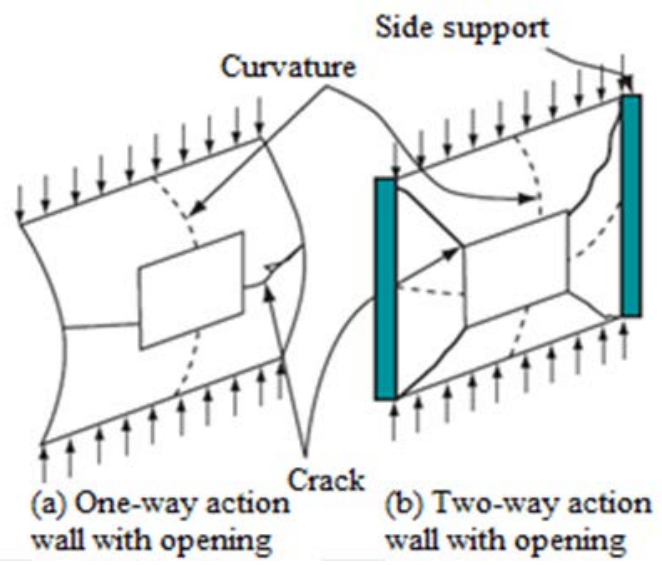

Fig.2 Eccentric load on RC wall (a) One-way action wall with opening, and (b) Two-way action wall with opening [18]

Pillai and Parthasarathy [19] investigated experimentally the behaviour of RC bearing wall panels in terms of the ultimate strength by considering many parameters including aspect ratio, steel reinforcement ratio, the compressive strength of concrete, strength of steel, and the eccentricity of the applied load. They compared the obtained results in terms of the ultimate strength with those values, which were evaluated using column theory and an empirical formula from the ACI Code. They stated that the column theory and the empirical formula provide very conservative results for concrete walls reinforced in one layer at the mid-thickness of the walls. However, this theory can provide good results in terms of the ultimate strength for walls of aspect ratio less than 30 if the stiffness of walls is taken as an uncracked section.

Zhilin [20] experimentally studied the shear strength of the lower chord of RC and pre-stressed concrete Vierendeel truss. He indicated that the lower chord of a Vierendeel truss under the applied load is subjected to the combined action of prestressed compression, large axial load, moment, and shear. Also, the practical formula for calculating the shear of the lower chord of the truss was proposed by considering the effect of the prestressed compression and longitudinal tension reinforcements.

Korol et al. [21] investigated the behaviour of Vierendeel joints in hollow members. Also, design curves for predicting the strength of joints were proposed. They stated that the unreinforced joint was not adequately behaving under the performed tests. Therefore, this type of joint needs a designed ratio of reinforcement. Besides, two types of connections were recommended to be used for the steel Vierendeel truss. These types are haunch and chord flange stiffeners, which have sufficient strength and stiffness characteristics.

Alwash [22] theoretically proposed a general nonlinear stiffness method for the analysis of RC frames. This study considered several parameters including geometric and material nonlinearity, shear effect, moment-axial forces interaction, unloading effect, and the effect of member end support. The proposed method was verified and validated by comparing the obtained theoretical results with those obtained from tests of RC Vierendeel truss models with different shapes and dimensions. He concluded that the proposed method is sufficient for modelling RC Vierendeel truss structures.

Doh [23] investigated experimentally and numerically the behaviour of normal and high strength RC walls in terms of the ultimate strength. The considered parameters were strengths of concrete, slenderness ratio, aspect ratio, reinforcement ratio, and eccentricity of loading. He developed a new design formula to predict the ultimate strength of RC walls considering the mentioned parameters. This formula was validated with the experimental and analytical results.

Zhaohul et. al. [24] investigated the Vierendeel truss under seismic effects. They stated that this type of frame has a good behaviour under seismic forces. Also, this frame can reduce the concentrated stresses at supports. Vierendeel truss can improve the ductility of portal frame.

Mahmod and Hameed [12] explored the behaviour of RC Vierendeel truss strengthened with steel fibres. The conducted parameters were aspect ratio, position, and volume fraction of the added fibres. They developed an analytical program to simulate the behaviour of the tested models. They stated that the use of steel fibres can improve toughness, crack resistance, tensile strength, and crack control of RC Vierendeel truss models. Also, these fibres cause an increase in the strength of models with a decrease in the corresponding deflection.

Mohammed et al. [25-27] stated that the load paths can be affected by the presence of openings in walls, which have concentrated stresses under the applied loading. These stresses are the main cause for the propagated cracks at the corner of openings. Thus, these regions of openings in RC walls are required to be strengthened. 
Shaker et al. 2012 [14] numerically investigated the behaviour of RC Vierendeel truss. They simulated reinforced concrete models that had been experimentally studied before. They stated that a good agreement was obtained between the experimental and analytical results. Also, they indicated that varying the shear transverse coefficients has more effects on the behaviour of Vierendeel truss in terms of open crack.

Hassan et al. 2019 [17] experimentally investigated the structural behaviour of precast RC Vierendeel walls of two types of concrete including high-strength self-compacted concrete (SCC) and RPC. Mainly, the considered parameters were the type of concrete and compressive strength. They stated that the deflection type of the tested panels was a single curvature. Also, the main reason for cracks at corners of walls is related to the concentrated stresses at the openings.

\section{GEOMETRY OF MODELS}

The properties of the numerical simulated models are based on the previously tested models [16]. These properties include geometry, opening locations, loads, and support conditions. The dimensions of all models have 1000, 750, and 75 $\mathrm{mm}$ for length, width, and depth, respectively. Table 1 illustrates the properties of the models and Fig. 3 shows the front and side views details of a typical wall model. Hence, Group 1 contains wall specimens that have various compressive strengths of NSC. However, Group 2 consists of wall models, which have different values of compressive strengths of RPC.

Table 1 Properties of models [16]

\begin{tabular}{cccc}
\hline Group No. & Symbols & $\begin{array}{c}\text { Concrete } \\
\text { type }\end{array}$ & $f_{\mathrm{c}}{ }^{\prime} \mathrm{MPa}$ \\
\hline \multirow{3}{*}{ Group 1 } & W1-1 & NSC & 33 \\
& W1-2 & NSC & 30 \\
& W1-3 & NSC & 28 \\
\hline \multirow{3}{*}{ Group 2 } & W1-4 & NSC & 25.8 \\
\hline & W2-1 & RPC & 65 \\
& W2-3 & RPC & 61 \\
& W2-4 & RPC & 70 \\
\hline
\end{tabular}

W: Wall; $i$ : Group number; $j$ : Model number; NSC: Normal strength concrete; RPC: Reactive powder concrete

\section{MECHANICAL PROPERTIES OF MATERIALS}

The mechanical properties of the simulated materials including concrete, and reinforcements reported by [16] are listed in Tables 2 and 3, respectively. Figs. 3 and 4 represent the geometry, layout, reinforcements, and opening location details for RC walls [16]. Fig.5 indicates the details of steel reinforcement and sections of the wall as stated in [16]

Table 2 Mechanical properties of concrete [16]

\begin{tabular}{cccccc}
\hline $\begin{array}{c}\text { Group } \\
\text { No. }\end{array}$ & $\begin{array}{c}f_{\mathrm{c}}{ }^{\prime} \\
\text { MPa }\end{array}$ & $\begin{array}{c}f_{\mathrm{t}} \\
\text { MPa }\end{array}$ & $\begin{array}{c}f_{\mathrm{r}} \\
\mathrm{MPa}\end{array}$ & $\begin{array}{c}E_{\mathrm{c}} \\
\text { MPa }\end{array}$ & $v$ \\
\hline 1 & 29 & 3.16 & 3.74 & 25105 & \\
2 & 66 & 5.26 & 5.66 & 38183 & 0.2 \\
\hline
\end{tabular}

Table 3 Mechanical properties of rebars [16]

\begin{tabular}{ccccc}
\hline $\begin{array}{c}\text { Rebar diameter } \\
(\mathrm{mm})\end{array}$ & $\begin{array}{c}f_{\mathrm{y}} \\
\mathrm{MPa}\end{array}$ & $\begin{array}{c}f_{\mathrm{u}} \\
\mathrm{MPa}\end{array}$ & $\begin{array}{c}E_{\mathrm{s}} \\
\mathrm{MPa}\end{array}$ & $v$ \\
\hline 10 & 421 & 520 & & \\
12 & 480 & 570 & 205000 & 0.3 \\
\hline
\end{tabular}
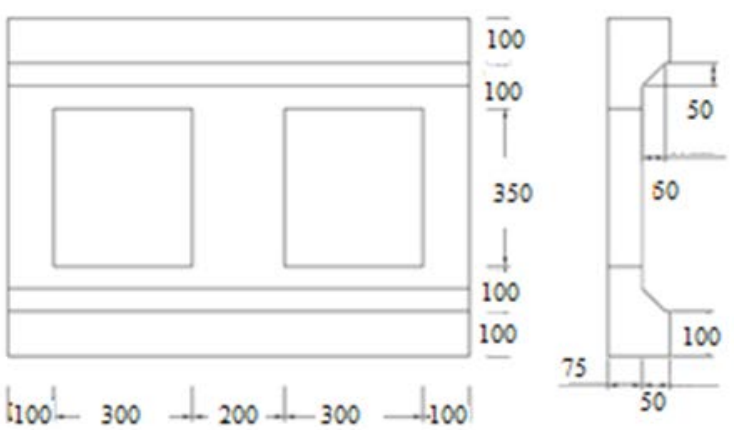

Note: All Dimensions in mm (b)
Fig.3 (a) Front view of wall panel dimensions, and (b) Side view of wall panel dimensions [16]

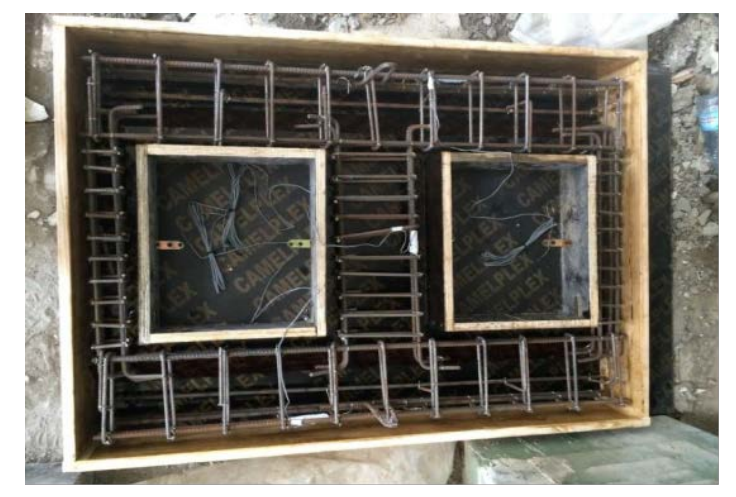

Fig.4 The formwork, reinforcements, and opening locations layout for a typical wall panel [16]

\section{ASSUMPTIONS}

The adopted assumptions in the numerical 
analysis of the RC Vierendeel truss wall are the isotropic and homogenous materials of reinforcement and concrete, reinforcement and surrounding concrete having the same nodes, i.e. without fractions between materials (discrete simulation of reinforcements), the plane sections remaining a plane, and an elastic-full plastic of the stress-strain for reinforcements.

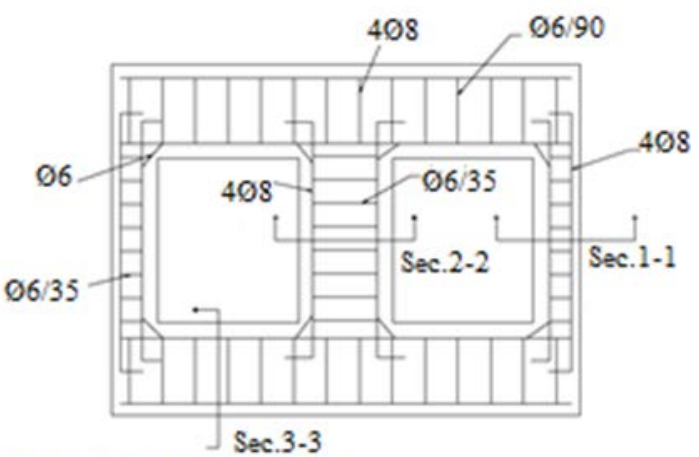

Note: All Dimensions in mm

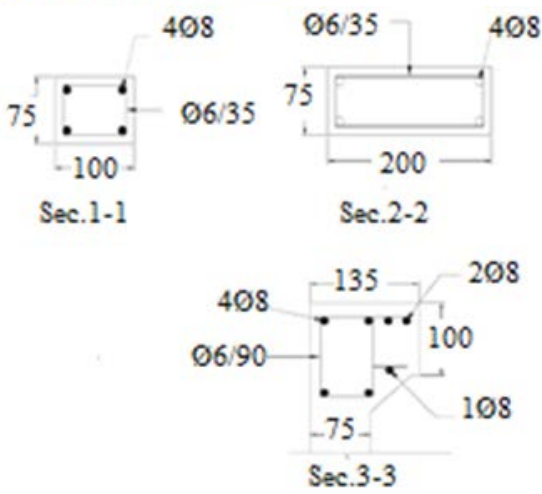

Fig.5 Details of a typical RC wall section [16]

\section{FINITE ELEMENTS MODELLING}

Numerical analysis involving the finite element approach was done by using ANSYS software [15] to simulate the conducted models. In the modeling process, the available elements were chosen to simulate the actual behaviors of the model's materials, supporting condition, and the applied loading. These materials include concrete, plate support, plate under loads, main reinforcements, and stirrups. SOLID65 element was selected for concrete material, which has three degrees of freedom at each node. LINK180 element was chosen to model all-steel reinforcements. SOLID185 was adopted to represent the steel plates, which are underneath the applied loads and supports [16].

Also, each model is usually divided into small elements, i.e. each element size of $15 \mathrm{~mm}$ in all directions by meshing. Besides, the connection between reinforcement nodes is similar to that of concrete solid nodes, in which the concrete and steel reinforcement nodes are merged. Typically, this technique can provide a perfect bond between the simulated materials. The tolerance value of 0.05 is used, in which the displacement controls during the nonlinear solution for convergence. The average load capacity of the simulated models is checked with that experimentally obtained from the previous study [16]. The whole behavior of the controlled model of normal strength concrete and those of high strength concrete subjected to eccentric distributed line load is compared with those of the experimental ones. The open and close coefficients for concrete cracks are 0.2 and 0.7 , respectively. The behavior of materials for steel rebars and concrete is anelastic-full plastic. This behavior for concrete is linear up to $0.3 f^{\prime}$ c, an elastic up to $0.85 f^{\prime}$ c, and full plastic up to 0.003 of the maximum value of concrete strain. The main assumptions of the numerical analysis are the plane section remaining a plane before and after applied loads, the homogeneity of concrete, full bonds between concrete and reinforcements, and ignoring the self-weight of the beam. Fig. 6 shows the wireframe for whole wall panels models components such as top, bottom chords, and stirrups reinforcements with supports condition as a simply supported wall.

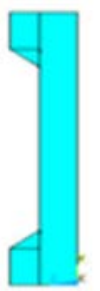

Step 1

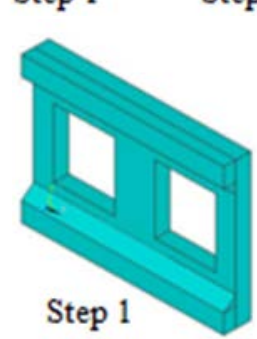

Step 2

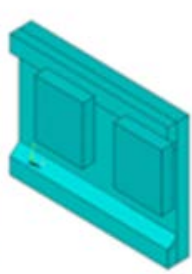

Step 3

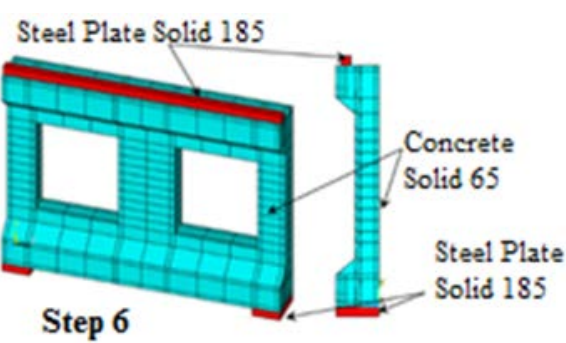

Fig.6 Finite element modelling procedures for a typical wall model

The left support is a roller and the right support 
is a pin, which has restrained in vertical and horizontal directions. In general, each model was created by ANSYS [15] using the following steps and they are shown in Fig. 6:

1- Creating an area according to the coordinates of the actual walls.

2- Extruding by the vertical direction on the created area to form the volume.

3- Locating the details and locations of the hole in the walls to be subtracted from the whole volume of walls.

4- Adding steel plate as a volume at the supports and the applied loading locations.

5- Identifying reinforcing rebars as lines and indicating a label for each type of rebar according to area or specification as shown in Fig. 7.

6- Starting meshing step for the concrete model and assigning the specifications of materials and elements as shown in Fig. 8.

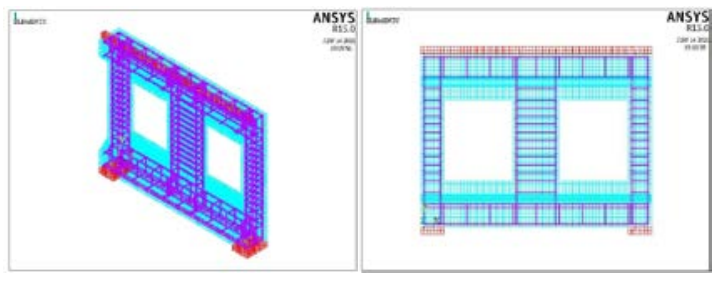

Fig.7 3D and front views for the main and stirrups reinforcements for all models

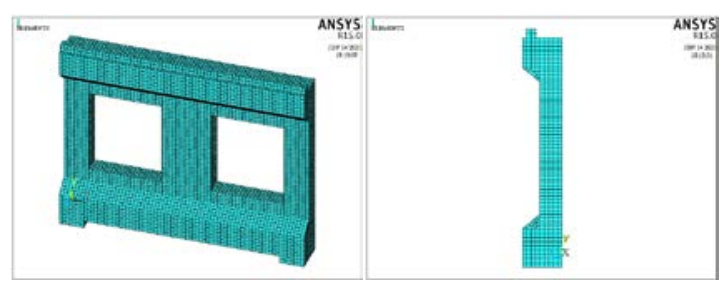

Fig.8 Front and side views of finite element mesh for a typical wall model

\section{RESULTS AND DISCUSSIONS}

Typical relations for the simulated models will be shown in this section to illustrate the effect of using various concrete strengths under the applied conditions on the structural behavior of RC walls. In general, the load versus deflection profiles for NSC and RPC models during the test, the applied load and the corresponding deflections at the center of the lower chord, at the center of the middle column, at the bottom edge of the specimen, and mid of the opening were recorded as shown in the following figures. Eight finite element models were analyzed by ANSYS software [15], which simulated the mechanical properties and the applied loads from the previous experimental tests study [16]. Based on the analysis results, all models were failed in shear. Fig. 9 shows the hydrostatic stress failure of the controlled wall, W1-1, which appears as diagonal stresses started from supports up to the locations of applied loads. In which, the stresses are concentrated at the supports and mid-span of the top and bottom chords. Also, these stresses increase at the openings of the top chord. However, Figs. 10 and 11 show the Von-misses stress and strain of the controlled wall, W1-1, respectively. The high stresses in Figs. 10 and 11 are concentrated at the supports, openings, and intersections between columns with the top and bottom chords of walls. The distributions of stresses are related to the loading transfer mechanism in the Vierendeel wall, which works as a truss $[17,28]$.

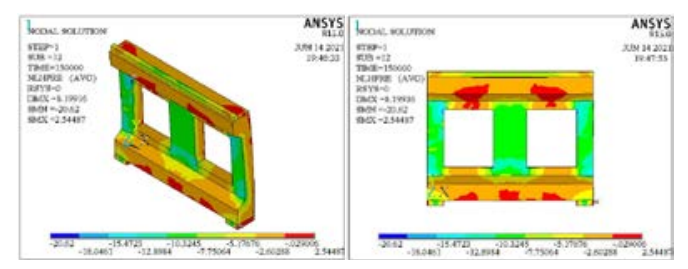

Fig.9 Hydrostatic stress of the controlled wall model W1-1 (3D and front views)

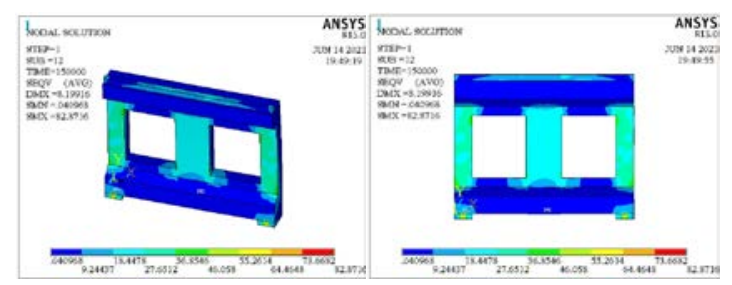

Fig.10 Von-Misses stress of the controlled wall model W1-1 (3D and front views)

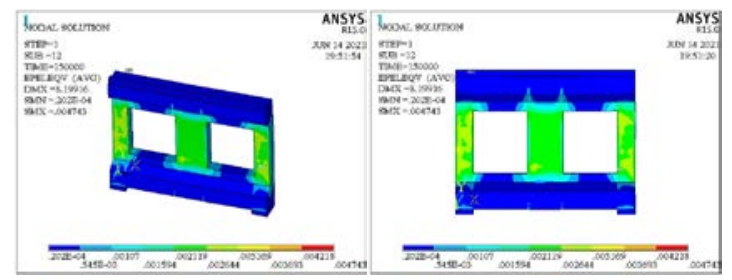

Fig.11 Von-Misses strain of the controlled wall model W1-1 (3D and front views)

Figs. 12 to 19 show the deflection at the first crack and failure load stages. The behaviour of RC walls indicated that the maximum deflection occurs in the middle underneath the models. The central deflection represents a cumulative deflection that was recorded from zero value at 
support to the middle point of the chord span between supports of columns. In general, the deflection values are higher in the top chord than in the bottom chord of walls due to the loading transfer mechanism. Also, the strength of concrete plays a vital role in varying the structural response of walls in terms of deflection. In which, RPC models have less deflection values in comparison with those of NSC models $[17,28]$.

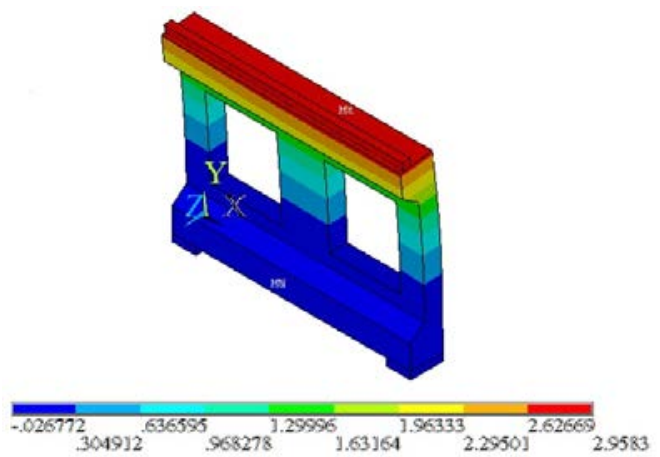

Fig.12 A 3D view for the deflection failure of the wall model W1-1

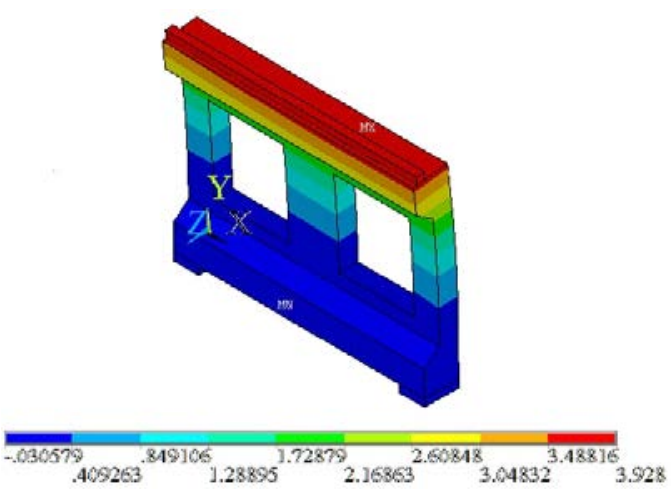

Fig.13 A 3D view for the deflection failure of the wall model W1-2

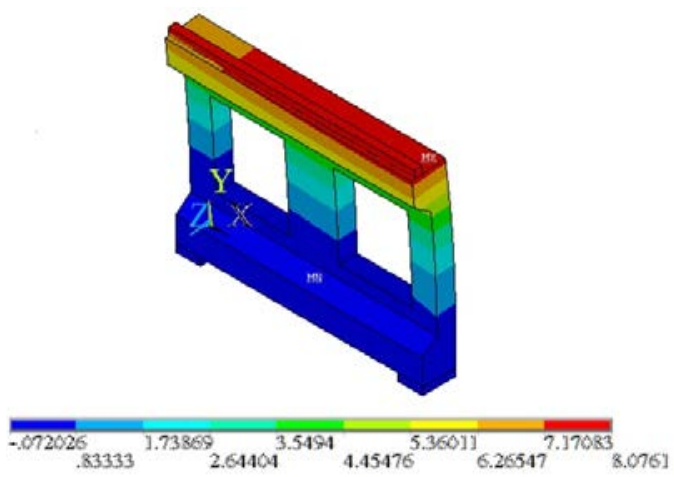

Fig.14 A 3D view for the deflection failure of the wall model W1-3

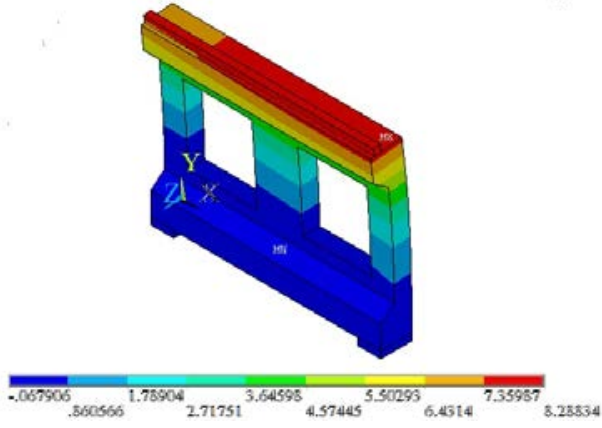

Fig.15 A 3D view for the deflection failure of the wall model W1-4

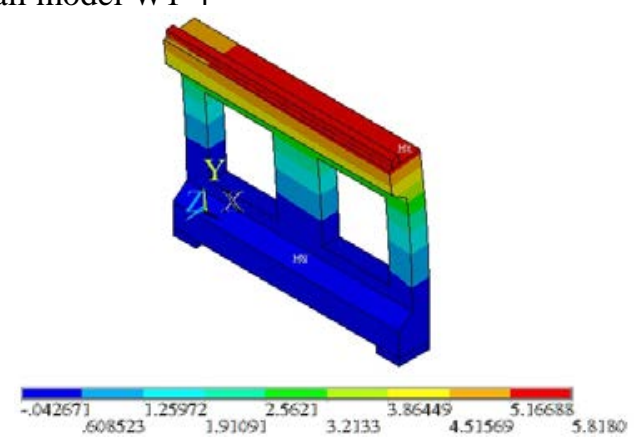

Fig.16 A 3D view for the deflection failure of the wall model W2-1

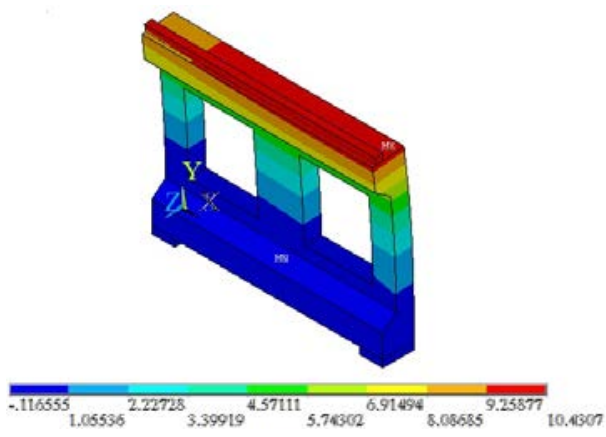

Fig.17 A 3D view for the deflection failure of the wall model W2-2

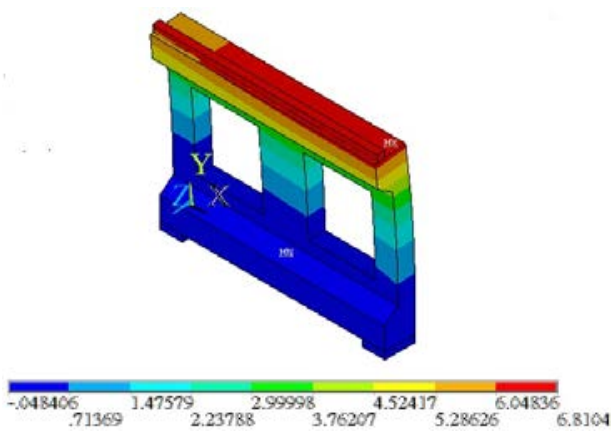

Fig.18 A 3D view for the deflection failure of the wall model W2-3 


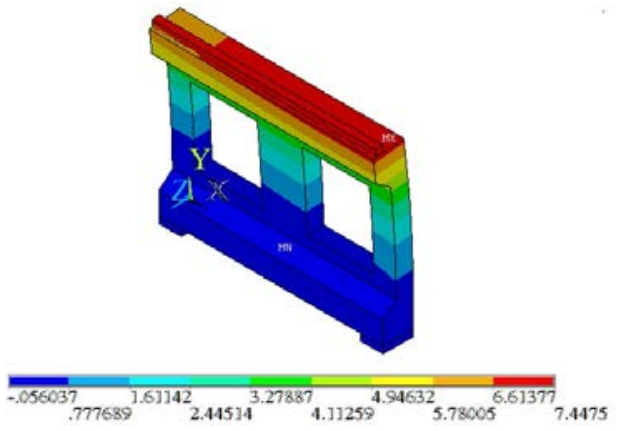

Fig.19 A 3D view for the deflection failure of the wall model W2-4

Figs. 20 and 21 show the propagating of cracks for the controlled wall of normal and high strength concrete. These cracks were compared with those from experimental tests [16]. These figures illustrate the following points:

1- The cracks developed due to an increase in the internal stress at the tension zone based on the ACI-318 [4] requirement for modulus of rupture as $\sqrt{0.62 f^{\prime} \mathrm{c}}$ and the concrete crush occurs when the internal stress at the compression zone become more than the characteristic compressive strength.

2- The strength of the NSC model is less than that of the RPC model.

3- The cracks at the tension face of RPC models are less than those of NSC models. Cracks in the tension face of columns are not straight. The cracks in the columns are more than the upper and lower chords. In the lower chord, the flexural cracks were first appearing. Then, shear cracks were appeared after increasing the applied loading.

4- The cracks in the tension face of columns were due to the bending moment formed relating to the eccentric axial load. Also, the cracks were increased according to the increase of loading.

5- The cracks in the compression face of specimens were appeared in the upper chord and started from the corner between the columns and upper chord with an angle of $45^{\circ}$. This is due to concentrated stress at the corners of the opening [25-27].

As stated, the load used in the numerical analysis was the same applied for all the tests considering the increment of $10 \mathrm{kN}$ [16]. Fig. 22 shows the positions of dial gauges in the experimental study [16]. Figs. 23 to 25 experimentally and numerically illustrate the comparison of relations between loads and the corresponding deflections for different strengths of models at the centre of the lower chord, i.e. D1.

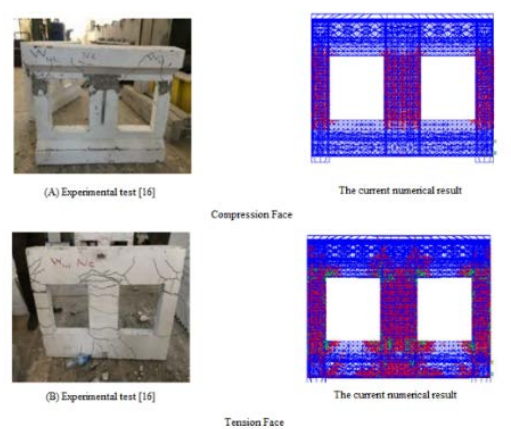

Fig.20 Cracks propagation and modes of failure at the end test stage for controlled NSC wall W1-1

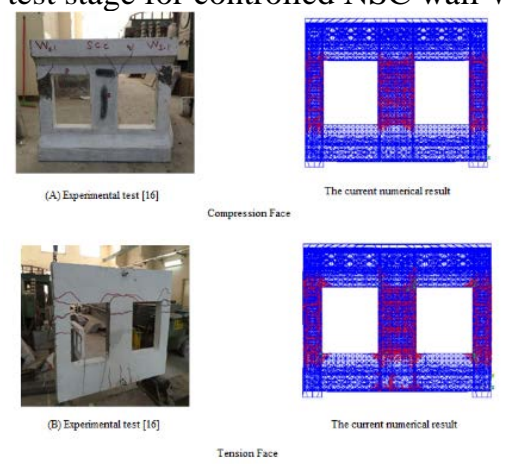

Fig.21 Cracks propagation and modes of failure at the end test stage for the controlled RPC wall W21

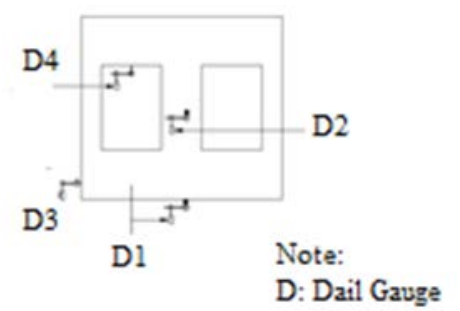

Fig.22 Positions of dial gauges [16]

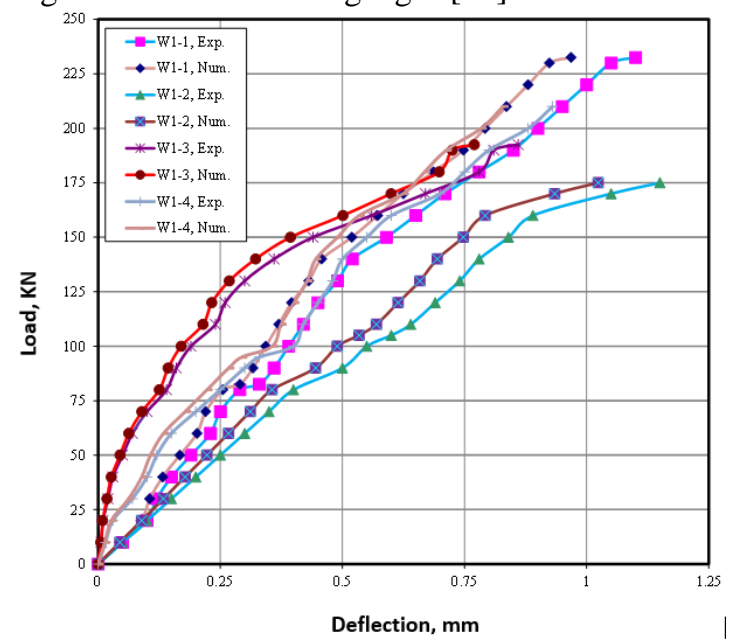

Fig.23 Comparison of experimental and numerical evaluation of load-deflection (Mid-span) at D1 for NSC models 


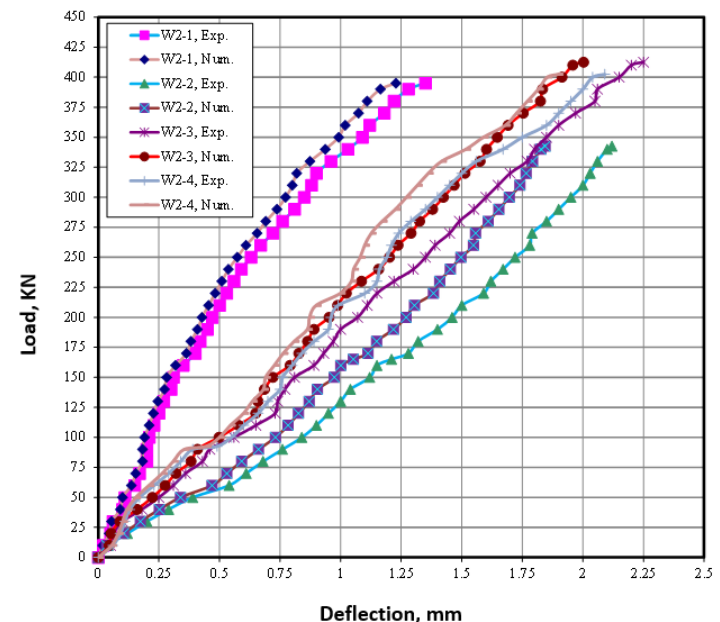

Fig.24 Comparison of experimental and numerical evaluation of load-deflection (Mid-span) at D1 for RPC models

Similarly, Figs. 26 to 28 experimentally and numerically show the comparison of relations between loads and the corresponding deflections at the center of the middle column, D2. However,
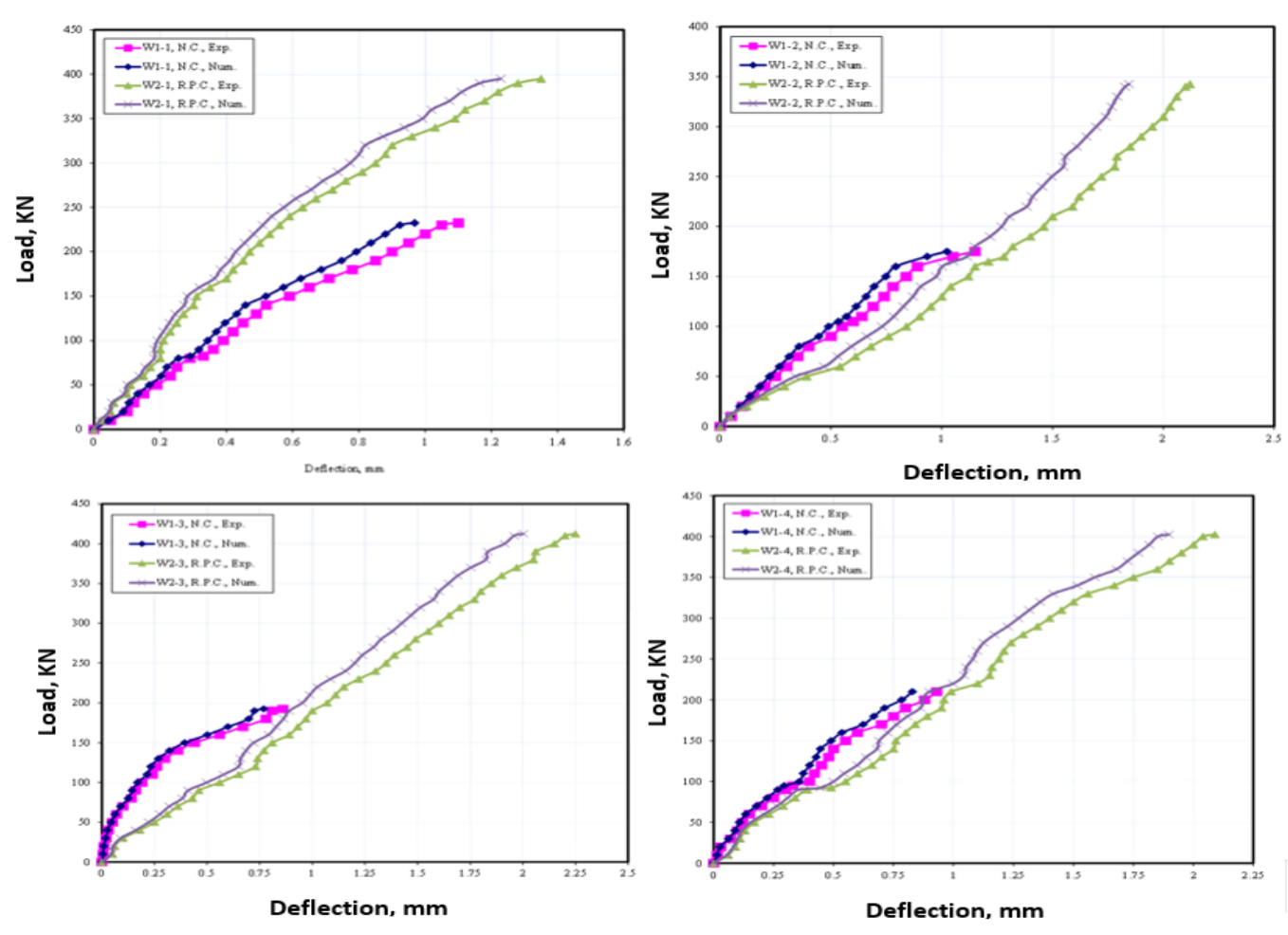

Fig.25 Comparisons of the experimental and numerical deflections for all models [W1-1 to W2-4] at the centre of the lower chord, D1

As shown in the stated figures, the first crack load differs for each model, which relies on the resistance of models to the applied load that leads to developing internal stresses inside the models. These stresses with increasing the applied loading
Figs. 29 to 31 experimentally and numerically show the comparison of relations between loads and the corresponding deflections at the edge of the specimen for recording the longitudinal displacement (Slipping), i.e. D3. Also, Figs. 32 to 34 experimentally and numerically show the comparison of relations between loads and the corresponding deflections at the center of the opening, e.g. D4. In which, Figs. 23, 26, 29, and 32 shows the primary cracking load varies between $30 \%$ and $60 \%$ of the total load for the NSC models. However, Fig. 24, 27, 30, and 33 shows that the same load ranges between $23 \%$ and $54 \%$ of the total load for the RPC models. The increase in the compressive strength of concrete in RPC models leads to increase the ultimate load capacity by $41 \%$ to $53 \%$ and a decrease in the corresponding deflection by $35 \%$ to $60 \%$ in comparison with NSC models. This increase is related to the content of silica fume and steel fibers in RPC models. These variations between the two groups of NSC and RPC models are combined in Figs. 25, 28, 31, and 34.

have become more than the modulus rupture of concrete, which leads to the propagation of cracks. Two groups' models including W1-1, W1-2, W13 , and W1-4 have approximately the same average compressive strength of concrete i.e. $f_{\mathrm{c}}{ }^{\prime}=$ $29 \mathrm{MPa}$, and the ultimate load capacity is less due 
to the decrease in the compressive strength of concrete in comparing with the high strength of reactive powder concrete. The normal strength concrete models have less strength capacity in shear and flexure.
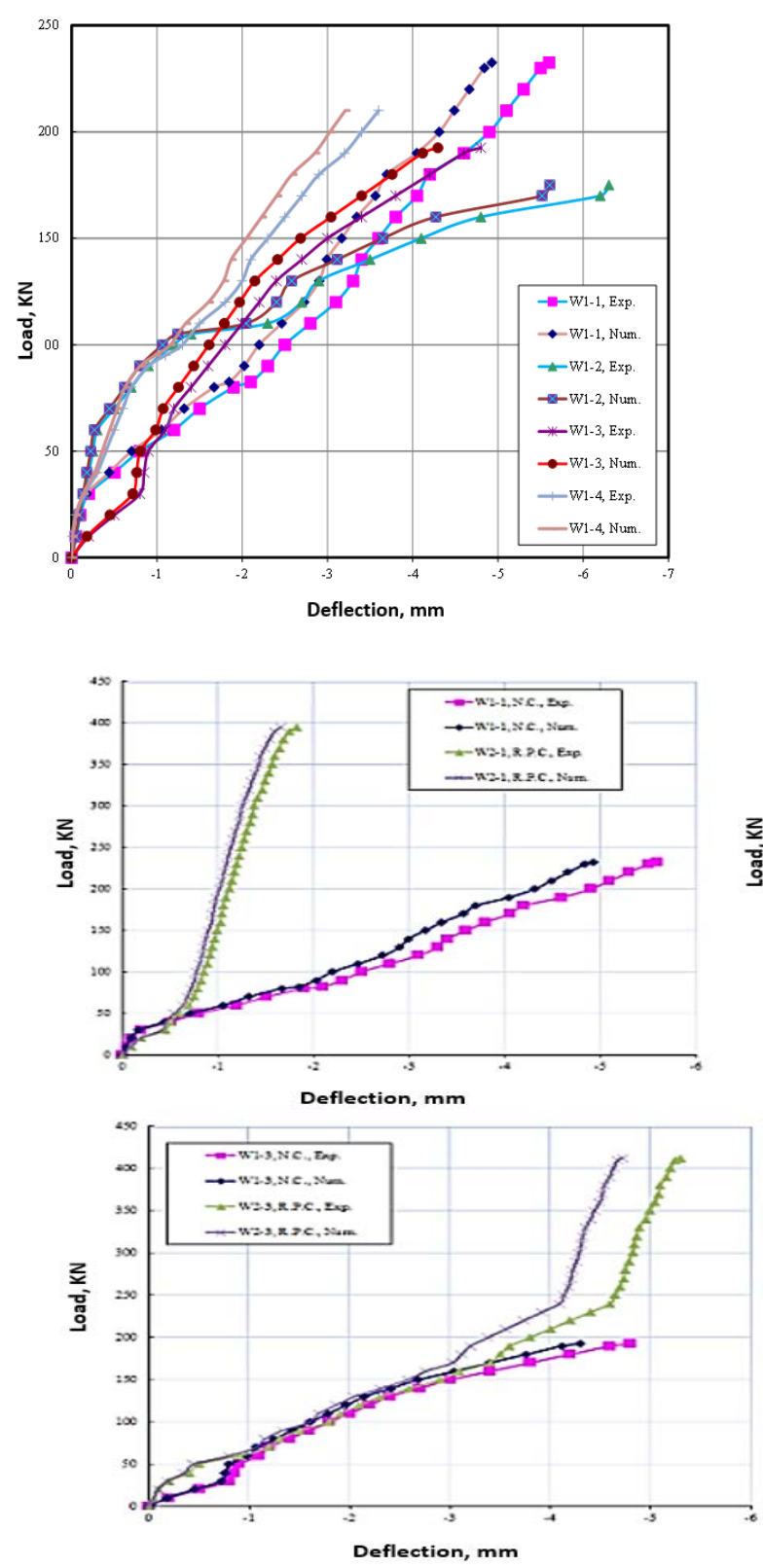

Fig.26 Comparison of experimental and numerical evaluation of load-deflection (Midspan) at D2 for NSC models

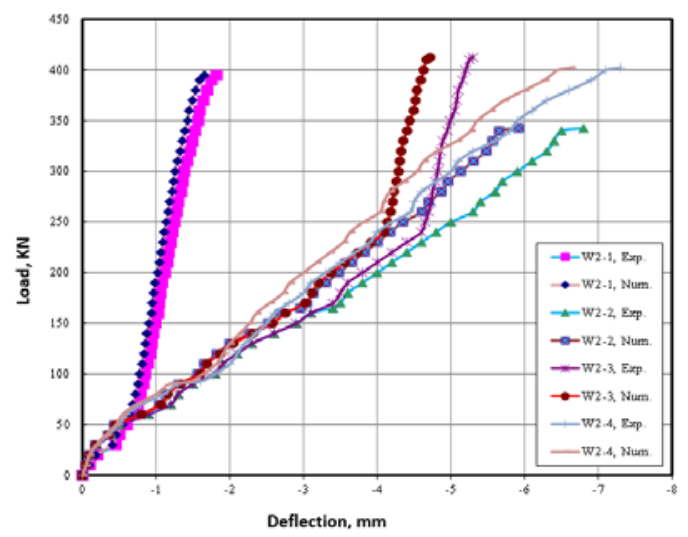

Fig.27 Comparison of experimental and numerical evaluation of load-deflection (Midspan) at D2 for RPC mode
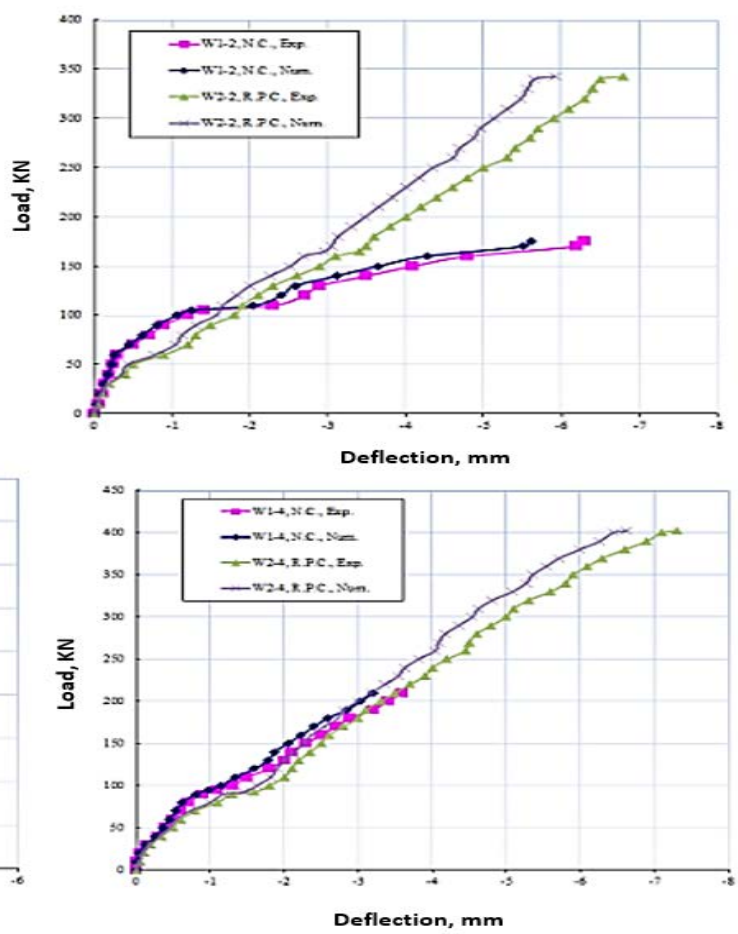

Fig.28 Comparisons of the experimental and numerical deflections for all models [W1-1 to W2-4] at the centre of the lower chord, D2

While the high-strength concrete models have more strength resistance than the normal ones. However, the behavior of models has the same trend of failure but with different intensities. In general, the behavior of all models starts as a linear up to the inflection point that represents the formation of the first crack. After this point, the model performance becomes toward the horizontal axis due to an increase in load and deflection, which leads to reduce the model stiffness up to failure. Also, the behavior of all models is nonlinear after the inflection point. Furthermore, Figs. 24 to 27 show RPC group and these figures provide the following points:

1- The strength of RPC models is more than those of NSC models.

2- The cracks in the tension face are more than 
those of the NSC group.

3- The cracks in the columns have different sizes, i.e. tiny, small and large. Also, the cracks are not straight. The cracks in the columns are more than the upper and lower chords. In the lower chord, flexural cracks appeared before the shear cracks.

4- Steel fibers prevent the progression of cracks.

5- The cracks in the tension face of columns were propagated due to the bending moment formed corresponding to the eccentric axial load. The cracks were increased concerning the increase of loading.

6- The cracks in the compression face of specimens were appeared in the upper chord and started from the corner between the columns and upper chord with an angle of $45^{\circ}$. This is due to the concentrated stress at the corners of the opening [25-27].

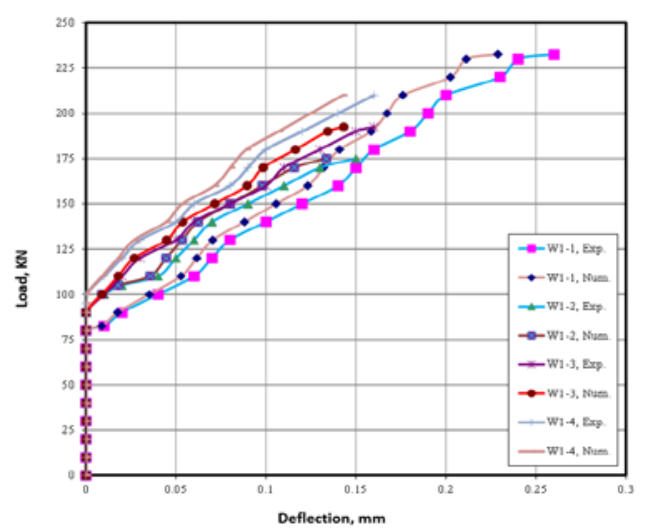

Fig.29 Comparison of experimental and numerical evaluation of load-deflection (Midspan) at D3 for NSC models

Table 4 lists the comparisons between the experimental and numerical results for the selected load-deflection behavior at the center of
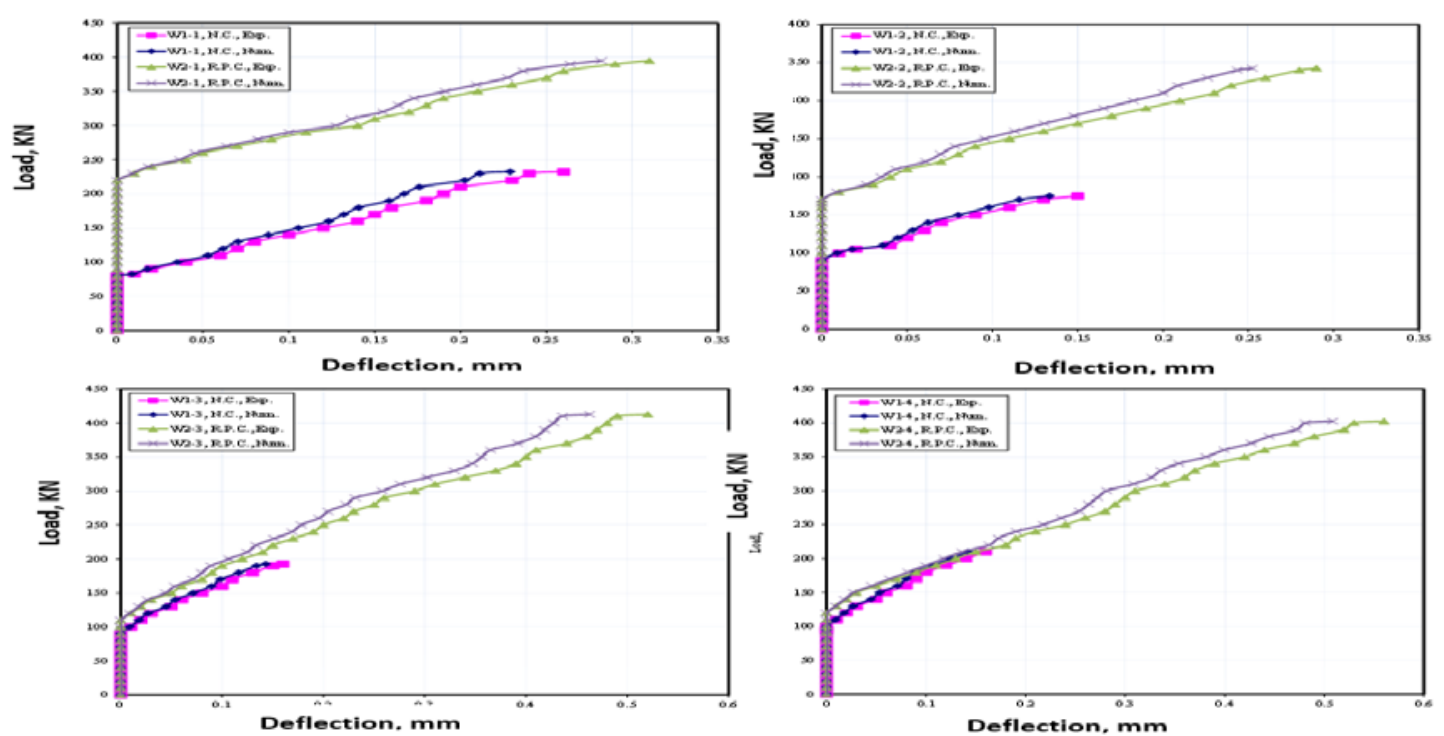

Fig.31 Comparisons of the experimental and numerical deflections for all models [W1-1 to W2-4] at the centre of the lower chord, D3

Fig.30 Comparison of experimental and numerical evaluation of load-deflection (Midspan) at D3 for RPC models

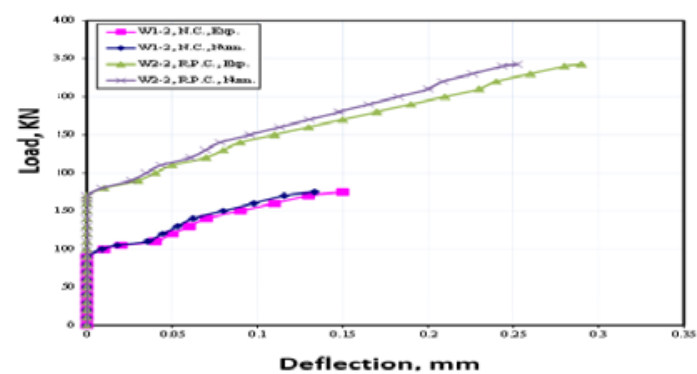
show a very good agreement. Moreover, Table 6 shows that the peak percentage of reduction in the deflection ductility index was obtained when changing the strength of models from NSC to RPC, which was about $94 \%$.

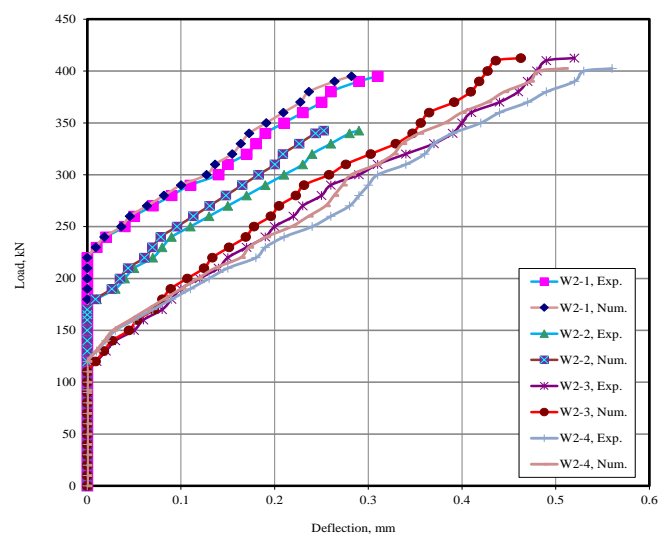
comparison of the first and failure deflections at the center of the opening, i.e. D4 are listed in mean and standard deviation values are indicated in the latter table, which illustrates the closeness of the numerical and experimental analysis results. Table 6 lists the ductility index of all models at ratio of midspan deflections at failure load to that midspan deflections at first crack load was calculated.

The values of the ductility index between the experimental and the numerical results indicate 


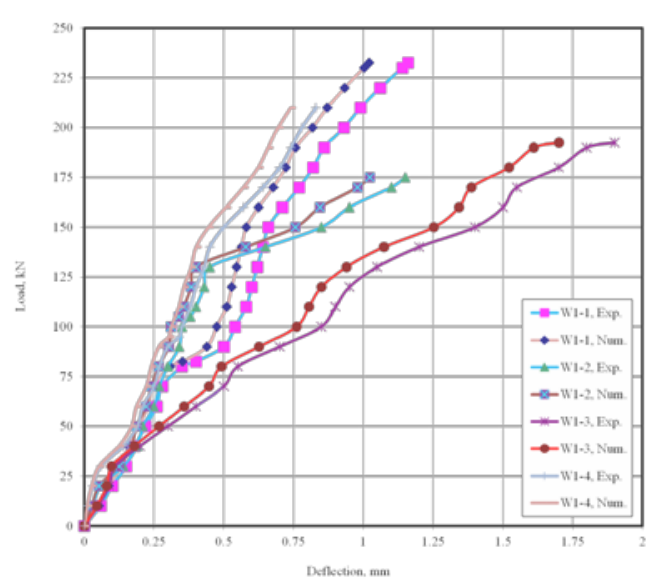

Fig.32 Comparison of experimental and numerical evaluation of load-deflection (Midspan) at D4 for NSC models
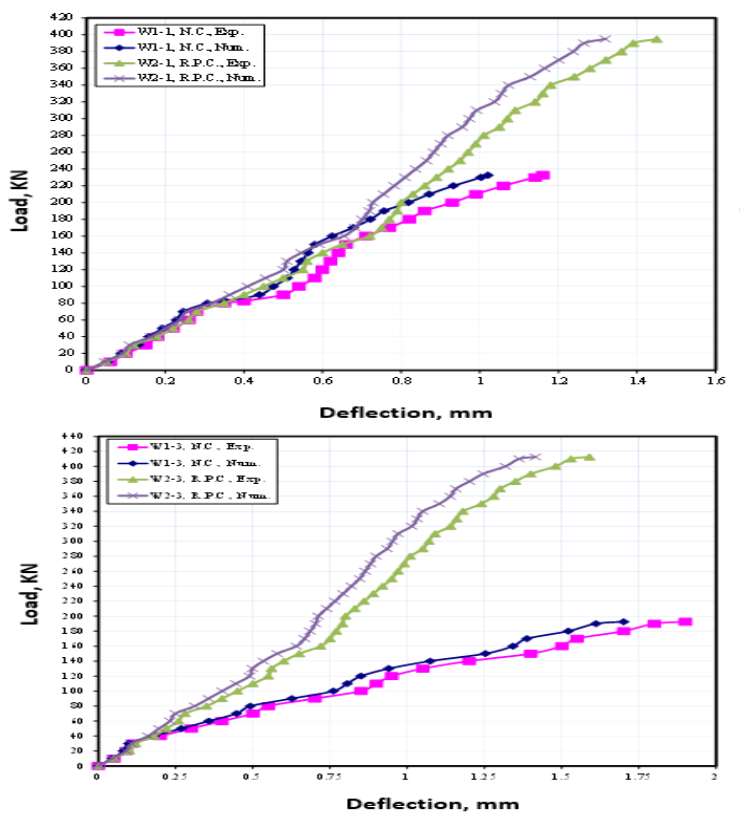

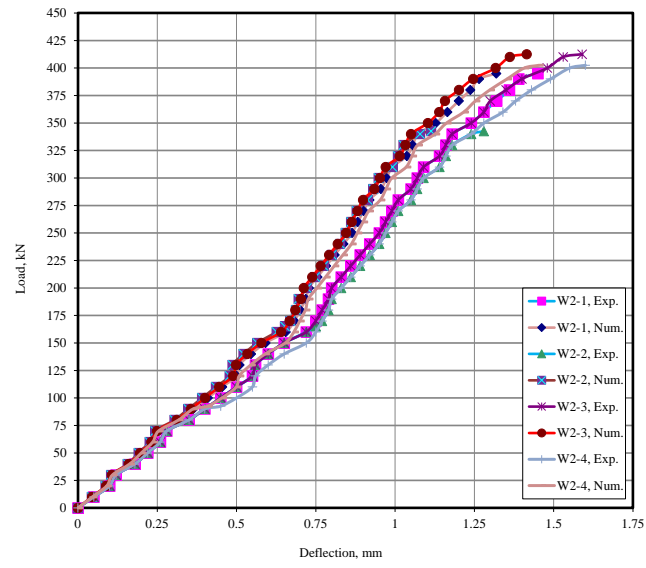

Fig.33 Comparison of experimental and numerical evaluation of load-deflection (Midspan) at D4 for RPC models
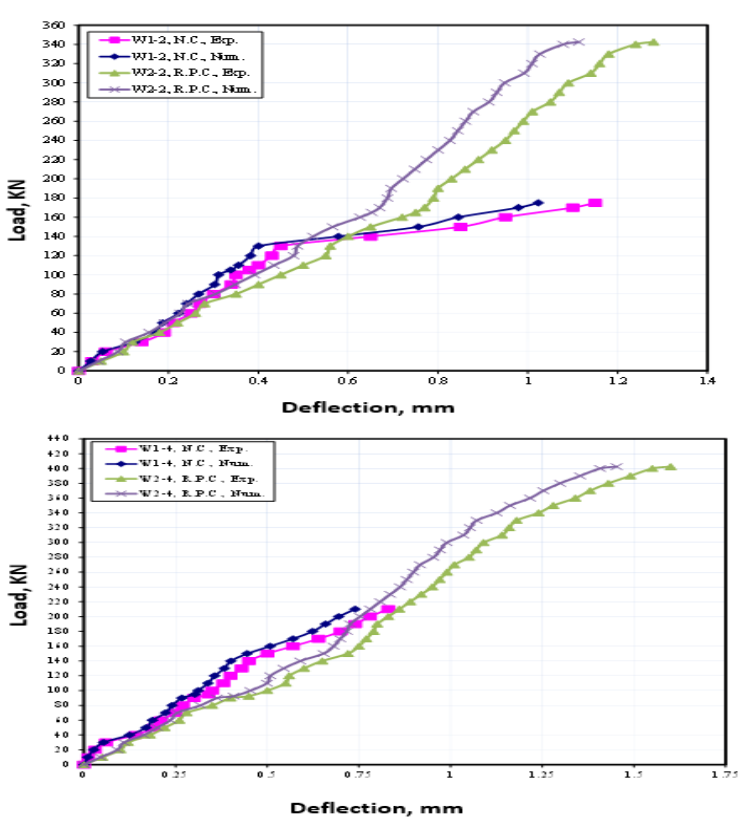

Fig.34 Comparisons of the experimental and numerical deflections for all models [W1-1 to W2-4] at the centre of the lower chord, D4

Table 4 Experimental and numerical comparison of the first and failure deflections at Midspan of D4

\begin{tabular}{ccccccccc}
\hline Symbols & $\begin{array}{c}\text { Concrete } \\
\text { type }\end{array}$ & $\begin{array}{c}f_{\mathrm{c}^{\prime}} \\
\mathrm{MPa}\end{array}$ & $\begin{array}{c}\text { Experimental } \\
{[16]-} \\
\text { numerical } \\
\text { loads, } \mathrm{kN}\end{array}$ & $\begin{array}{c}\text { Experimental } \\
\text { deflection, } \\
\text { mm [16] }\end{array}$ & $\begin{array}{c}\text { Numerical } \\
\text { deflection, } \\
\mathrm{mm}\end{array}$ \\
\hline W1-1 & NSC & 33 & 82.5 & 232.5 & 0.14 & 1.16 & 0.126 & 1.14 \\
\hline W1-2 & NSC & 30 & 105 & 175 & 0.18 & 1.15 & 0.171 & 1.13 \\
\hline W1-3 & NSC & 28 & 90 & 192.5 & 0.25 & 1.93 & 0.23 & 1.9 \\
\hline W1-4 & NSC & 25.8 & 95 & 210 & 0.05 & 0.83 & 0.046 & 0.75 \\
\hline W2-1 & PRC & 65 & 210 & 395 & 0.15 & 1.45 & 0.144 & 1.37 \\
\hline W2-2 & PRC & 61 & 165 & 342.5 & 0.16 & 1.28 & 0.155 & 1.21 \\
\hline W2-3 & PRC & 70 & 100 & 412.5 & 0.18 & 1.59 & 0.168 & 1.53 \\
\hline W2-4 & PRC & 67 & 92.5 & 402.5 & 0.19 & 1.62 & 0.183 & 1.54 \\
\hline
\end{tabular}

Hence, the variety in deflection values between specimens in Tables 5 and 6 is related to the compressive strength of concrete used in the models as stated in Table 4.

\section{CONCLUSIONS}

In this study, numerical analyses for a specified number of models were performed and verified with those models of experimental tests, which were conducted in a previous study. Based on these analyses, the following conclusion can be drawn:

- The numerical approach can be an accurate method for predicting the structural behaviour of different types of structural elements by 
considering the appropriate assumptions, modeling procedure, and conditions of the real elements.

Table 5 Statistical comparison of experimental and numerical of the first and failure deflections at Midspan of D4

\begin{tabular}{|c|c|c|c|c|c|c|}
\hline \multirow[t]{2}{*}{ Symbols } & \multicolumn{2}{|c|}{$\begin{array}{c}\text { Experimental } \\
\text { deflection, } \mathrm{mm}[16]\end{array}$} & \multicolumn{2}{|c|}{$\begin{array}{c}\text { Numerical } \\
\text { deflection, mm }\end{array}$} & \multicolumn{2}{|c|}{$\begin{array}{c}\text { Ratio of } \\
\text { numerical/experimental }\end{array}$} \\
\hline & First & Failure & First & Failure & First & Failure \\
\hline W1-1 & 0.14 & 1.16 & 0.126 & 1.14 & 0.9 & 0.983 \\
\hline W1-2 & 0.18 & 1.15 & 0.171 & 1.13 & 0.95 & 0.982 \\
\hline W1-3 & 0.25 & 1.93 & 0.23 & 1.9 & 0.91 & 0.984 \\
\hline W1-4 & 0.05 & 0.83 & 0.046 & 0.75 & 0.92 & 0.903 \\
\hline W2-1 & 0.15 & 1.45 & 0.144 & 1.37 & 0.96 & 0.944 \\
\hline W2-2 & 0.16 & 1.28 & 0.155 & 1.21 & 0.968 & 0.945 \\
\hline W2-3 & 0.18 & 1.59 & 0.168 & 1.53 & 0.933 & 0.962 \\
\hline \multirow[t]{4}{*}{ W2-4 } & 0.19 & 1.62 & 0.183 & 1.54 & 0.963 & 0.950 \\
\hline & & \multicolumn{3}{|c|}{ Mean } & 0.938 & 0.956 \\
\hline & & \multicolumn{3}{|c|}{ Standard deviation } & 0.0259 & 0.0275 \\
\hline & & \multicolumn{3}{|c|}{ Variance } & 0.000591 & 0.00066 \\
\hline
\end{tabular}

Table 6 Statistical comparison of experimental and numerical of the first and failure deflections at Midspan of D4

\begin{tabular}{cccccccc}
\hline Symbols & $\begin{array}{c}\text { Experimental } \\
\text { deflection, mm } \\
\text { [16] }\end{array}$ & $\begin{array}{c}\text { Ductility } \\
\text { index }\end{array}$ & $\begin{array}{c}\text { Numerical } \\
\text { deflection, } \\
\text { mm }\end{array}$ & $\begin{array}{c}\text { Ductility } \\
\text { index }\end{array}$ & $\begin{array}{c}\text { Ductility index ratio of } \\
\text { numerical/experimental }\end{array}$ \\
\hline & First & Failure & Experimental & First & Numerical \\
\hline W1-1 & 0.14 & 1.16 & 8.286 & 0.126 & 1.092 & 9.047 & 1.092 \\
\hline W1-2 & 0.18 & 1.15 & 6.388 & 0.171 & 1.034 & 6.608 & 1.034 \\
\hline W1-3 & 0.25 & 1.93 & 7.72 & 0.23 & 1.070 & 8.261 & 1.070 \\
\hline W1-4 & 0.05 & 0.83 & 16.6 & 0.046 & 0.982 & 16.304 & 0.982 \\
\hline W2-1 & 0.15 & 1.45 & 9.666 & 0.144 & 0.984 & 9.514 & 0.984 \\
\hline W2-2 & 0.16 & 1.28 & 8 & 0.155 & 0.975 & 7.806 & 0.975 \\
\hline W2-3 & 0.18 & 1.59 & 8.833 & 0.168 & 1.031 & 9.107 & 1.031 \\
\hline W2-4 & 0.19 & 1.62 & 8.526 & 0.183 & 0.986 & 8.415 & 0.986 \\
\hline & \multicolumn{7}{c}{ Mean } \\
\hline \\
\hline \multicolumn{7}{c}{ Standard deviation } \\
\hline
\end{tabular}

- $\quad$ The obtained numerical structural behaviours of RC walls in terms of the ultimate strength, cracking patterns, deflections, and mode of failure have a very good agreement with those behaviours, which were experimentally evaluated in the previous study. This agreement has been verified through statistical terms, e.g. mean and standard deviation values.

- The ultimate strengths or failure loads of RPC models are more than those strengths of NSC models due to the ductile behaviour of the former models.

- The progression of cracks is more effective in NSC models than that progression in RPC models due to the high strength of the latter models under the same value of the applied loads.

- The cracks in the tension face of columns are more than those cracks in the upper and bottom chords of the wall models. This is because of the eccentricity and the progressive increase of the applied loading. however, the cracks in the compression face of models between the upper chord and the columns are due to the concentrated stresses at the corner of openings.

- The mode of failure in all models was at the intersection between the upper chord and columns.

- $\quad$ The deflection failure in all models was in a vertical shape and single curvature.

\section{ACKNOWLEDGMENTS}

The authors would like to thank Mustansiriyah University (www.uomustansiriyah.edu.iq)

Baghdad-Iraq, for its support in the present work.

\section{REFERENCES}

[1] Saheb SM, Desayi P. Ultimate strength of RC wall panels in one-way in-plane action. J Struct Eng, 1989.

[2] Rodrigues EV. Determination of Ultimate Compression Resistance of Concrete Laminar Enveloped Panels. MSc thesis, Minas Gerais University, Brazil, 2009.

[3] Wallace JW. Modelling issues for tall reinforced concrete core wall buildings. Struct. Design Tall Spec. Build., Vol.16: pp.615-632, 2007. https://doi.org/10.1002/tal.440.

[4] Erfan AM, Abd Elnaby RM, Elhawary A, ElSayed TA, Improving the compressive behavior of RC walls reinforced with ferrocement composites under centric and eccentric loading. Case Studies in Construction Materials, 2021, doi: https://doi.org/10.1016/j.cscm.2021.e00541.

[5] Aliewi JM. Time-Dependent Finite Element Analysis of Base- Restrained Reinforced Concrete Walls. MSc thesis, University of Technology, Baghdad, Iraq, 2006.

[6] ACI Committee 318. Building Code Requirements for Structural Concrete. 2014.

[7] Wight JK, MacGregor JG. Reinforced Concrete: Mechanics and Design. 2009.

[8] British Standards Institution (BSI). BS 81101: Structural Use of Concrete Part 1: Code of Practice for Design and Construction, 2005.

[9] Federal Emergency Management Agency (FEMA). FEMA P-749 Earthquake-Resistant Design Concepts. 2010.

[10] Yakut A. Reinforced Concrete Frame Construction. World Housing Encyclopedia, Summary Publication, pp.9-1 to 9-8, 2004.

[11] Basha HS, Goel SC. Special truss moment frames with Vierendeel middle panel. Eng Struct. Vol.17, pp.352-8, 1995.

[12] Mahmod KS., Hameed AW. Nonlinear analysis of reinforced fibrous concrete vierendeel truss. J Eng, Vol.14, 2008.

[13]Kumar R, Shaoo DR. Seismic fragility of 
steel special truss moment frames with multiple ductile vierendeel panels. Soil Dynamics and Earthquake Engineering, Vol.143, 2021, https://doi.org/10.1016/j.soildyn.2021.106603

[14] Shaker QM, Kamonna, HHH, Attia MA. Nonlinear analysis of reinforced concrete Vierendeel truss. Kufa Journal of Engineering, Vol.4, No.1, pp.1-19, 2012.

[15] ANSYS, Inc. ANSYS Fluent User's Guide, Release 17.2, 2016.

[16] Abdul Ameer JS, Ghadhban HN, Hassan MA. Structural behavior of reinforced concrete vierendeel truss to use in precast construction. J Eng Sustain Dev, Vol.21, No.6, pp.131-47, 2017.

[17] Hassan MA, Nasir H, Saeed J. Experimental investigation of high strength precast reinforced concrete walls used (Vierendeel truss form). Mater Sci Eng, Vol.584, 2019.

[18] Fragomeni S, Doh JH, Lee DJ. Behavior of axially loaded concrete wall panels with openings: An experimental study. Adv Struct Eng, 2012.

[19]Pillai SU, Parthasarathy C V. Ultimate strength and design of concrete walls. Build Environ, 1977.

[20] Zhilin Y. Shear strength of the lower chord of the reinforced concrete and pre-stressed concrete vierendeel truss (Discussion on shear strength of eccentrical tension members), Journal of Building Structures, Vol. 2, 1980.

[21] Korol RM, Shehata AA, Mirza FA. Inelastic finite element analysis of vierendeel trusses of rectangular hollow sections, In: Brebbia C.A., Keramidas G.A. (eds) Computational Methods and Experimental Measurements.
Springer, Berlin, Heidelberg, 1984.

[22] Alwash NAH. Nonlinear Behavior and Optimal Design of Reinforced Vierendeel Trusses. PhD thesis, University of Technology, Baghdad, Iraq, 1995.

[23] Doh JH. Experimental and Theoretical Studies of Normal and High Strength Concrete Wall Panels. PhD thesis, Griffith University, Queensland, Australia, 2003.

[24]Zhaohul, C, Xueyi F, Xiangbing Y, Songliang $C$ and Lei G, Study on Steel Reinforced Concrete Vierendeel Portal Structure- Portal Structure Design of Shenhen University Science and Technology Building", Journal of Building Structures, Vol.25, No.2, 64-71, 2004.

[25] Mohammed BS, Abu Bakar BH, Choong KK. Behaviour of axially loaded firedclay masonry panels with web openings. Indian Concr J; Vol.83, No.4, pp.9-16, 2009.

[26] Mohammed BS, Abu Bakar BH, Choong KK. The effects of opening on the structural behavior of masonry wall subjected to compressive loading - strain variation. Open Civil Eng J;Vol.3, No.12, pp.62-73, 2009.

[27] Mohammed BS, Ean LW, Malek MA. One way RC wall panels with openings strengthened with CFRP, Construction and Building Materials, Vol.40, pp.575-583, 2013.

[28]Hassan MAH, Experimental Structural Behavior of Vierendeel Truss used instead of Bearing Wall in Precast Construction. MSc thesis, Mustansiriyah University, Baghdad, Iraq, 2016.

Copyright (C) Int. J. of GEOMATE All rights reserved, including making copies unless permission is obtained from the copyright proprietors. 